\title{
Precipitation of hypercalcaemia in sarcoidosis by foreign sun holidays: report of four cases
}

\author{
Cornelius C. Cronin, Sean F. Dinneen, M. Sinéad O'Mahony, \\ Charles P. Bredin and Denis J. O'Sullivan
}

Departments of Medicine and Respiratory Medicine, Regional Hospital, Cork.

\begin{abstract}
Summary: Hypercalcaemia after foreign sun holidays in four patients is described. Although only one was a known case, all had sarcoidosis. The pathogenic mechanisms are discussed and the implications of excessive sun exposure for the mode of presentation and the management of sarcoidosis are highlighted.
\end{abstract}

\section{Introduction}

The association between sunlight exposure and hypercalcaemia in sarcoidosis, although long recognized, ' has not been much emphasized. The mechanism whereby hypercalcaemia occurs in sarcoidosis has been clarified, ${ }^{2}$ allowing an understanding of the pathological role of sunlight exposure and of the therapeutic role of corticosteroids. We describe four patients who, during or after foreign holidays in the sun, developed hypercalcaemia, in all of whom symptoms were sufficiently severe to require hospital admission. For three patients it was the mode of presentation of their sarcoidosis.

\section{Case reports}

Case 1

A 22 year old factory worker on holiday in Gran Canaria was admitted to hospital there with vomiting and severe abdominal pain. He was dehydrated and hypotensive. Acute haemorrhagic pancreatitis was diagnosed by abdominal computed tomographic (CT) scan. He developed a paralytic ileus and a pancreatic pseudocyst. As his condition stabilized, hyperglycaemia and hypercalcaemia were noted and treated with insulin and calcitonin, respectively.

Four weeks after admission, he was transferred to this hospital with a provisional diagnosis of hyperparathyroidism. On examination, he was

Correspondence: C.C. Cronin, M.B., M.R.C.P.I., Department of Medicine, Cork Regional Hospital, Wilton, Cork.

Accepted: 21 September 1989 deeply sun-tanned, malnourished with prominent muscle wasting, and had tender hepatosplenomegaly. Serum creatinine was $151 \mu \mathrm{mol} / 1$ (normal range: 50-130), glomerular filtration rate was $50 \mathrm{ml} / \mathrm{min}$ (NR: $60-180$ ), and fasting non-tourniquet serum calcium ranged as high as $4.05 \mathrm{mmol} / \mathrm{l}$ (NR: 2.10-2.62). Chest $X$-ray showed diffuse pulmonary infiltration and transbronchial lung biopsy interstitial fibrosis and abundant noncaseating granulomata, consistent with sarcoidosis. Hypercalcaemia responded to corticosteroids and renal function reverted to normal. When steroids were discontinued, he remained normocalcaemic but insulin dependent.

\section{Case 2}

While on holiday in Spain, a 27 year old office worker had nausea, vomiting and thirst. On return to this country, he was admitted to hospital with abdominal pain. Serum calcium was $3.60 \mathrm{mmol} / \mathrm{l}$. Sarcoidosis was suggested by diffuse pulmonary infiltration on chest radiography and confirmed by non-caseating granulomata on liver biopsy.

Hypercalcaemia responded to corticosteroids. On three occasions over succeeding years, when attempts were made to reduce his steroid dosage, he again developed hypercalcaemia, not obviously related to sun exposure. When steroids were finally discontinued, he went on further sun holidays against medical advice without, however, adverse consequences.

Case 3

A 30 year old factory worker was found, after a minor road traffic accident, to have peri-hilar pulmonary mottling on chest X-ray. Scalene lymph 
node biopsy was consistent with sarcoidosis. He was normocalcaemic. Six months later, following a foreign holiday, while on $5 \mathrm{mg}$ prednisolone daily, he was admitted to hospital with vomiting, constipation, polydipsia and polyuria. On examination, he was deeply sun-tanned, dehydrated and had a palpably enlarged spleen. Serum calcium was $3.61 \mathrm{mmol} / \mathrm{l}$ and serum creatinine $260 \mu \mathrm{mol} / \mathrm{l}$. Hypercalcaemia and renal insufficiency responded to intravenous fluids, diuretics and corticosteroids.

The patient's compliance with medication was erratic. In each of the succeeding three summers, without travelling abroad, he was hypercalcaemic with polydipsia, polyuria and prominent malaise. In winter, he was normocalcaemic, without medication.

\section{Case 4}

An 18 year old student, after a Spanish holiday, had vomiting and constipation. He was dehydrated and had generalized lymphadenopathy. Serum calcium was $3.33 \mathrm{mmol} / \mathrm{l}$. Chest X-ray showed bi-hilar lymphadenopathy and cervical lymph node biopsy was consistent with sarcoidosis. Ten months later, after a holiday in Greece, he presented with similar symptoms. Serum calcium was $3.63 \mathrm{mmol} / \mathrm{l}$. In the following summer, which he spent in Ireland, serum calcium was $4.26 \mathrm{mmol} / \mathrm{l}$, with relatively mild symptoms. On each occasion, he responded to corticosteroids. Subsequently, on maintenance steroids, he has remained normocalcaemic.

\section{Discussion}

Disorders of calcium metabolism are well-recognized in sarcoidosis. Hypercalcaemia occurs in $10 \%$ of patients ${ }^{2}$ and hypercalciuria in up to $60 \%$. $^{3}$ These patients illustrate the spectrum of the clinical consequences of hypercalcaemia, from troublesome malaise during the summer months to lifethreatening acute haemorrhagic pancreatitis. The cause of hypercalcaemia in sarcoidosis has recently been unravelled. ${ }^{2}$ It had been accepted that endorgan hypersensitivity to the effects of vitamin D was the basis of hypercalcaemia in this condition.
The finding of increased levels of 1,25-dihydroxyvitamin $\mathrm{D}_{3}$, the active hormone, in hypercalcaemic sarcoidosis suggested, however, a quantitative rather than a qualitative increase in vitamin $D$ action. ${ }^{3,4}$ Furthermore, a similar finding in an anephric patient with sarcoidosis and hypercalcaemia pointed to extra-renal generation of 1,25-dihydroxyvitamin $\mathrm{D}_{3}{ }^{5}$ The pivotal study by Adams et al. demonstrated that cultured alveolar sarcoid macrophages metabolize 25-hydroxyvitamin $\mathrm{D}_{3}$ to 1,25-dihydroxyvitamin $\mathrm{D}_{3}{ }^{6} \mathrm{~A}$ similar reaction was subsequently shown in sarcoid lymph node homogenate. ${ }^{7}$ Sunlight exposure through its antirachitic action increases the substrate for this reaction, resulting in increased circulating active hormone and hypercalcaemia. Glucocorticoids inhibit this reaction in sarcoid tissue. They rapidly lower levels of 1,25-dihydroxyvitamin $\mathrm{D}_{3}$ in sarcoidosis (before lowering calcium levels) without affecting 25-hydroxyvitamin $D_{3}$ levels; ${ }^{8}$ thus, their therapeutic efficacy in this situation.

In each of the patients described above, there was a clear-cut relationship between exposure to the intense and prolonged solar radiation of foreign sun holidays and the development of symptomatic hypercalcaemia. There have been isolated reports of such an association, usually noted as an incidental finding. ${ }^{8,9}$ With the popularity of such holidays, advising patients with sarcoidosis to avoid excessive sun exposure has not, we believe, been sufficiently emphasized. It seems reasonable to offer such advice to patients with previously documented hypercalcaemia and to those with recent onset, widespread or active disease. It may be that hypercalciuria provides a marker for those sensitive to sun exposure and at risk of hypercalcaemia.

Finally, it is notable that, before developing sunlight-induced hypercalcaemia, only one of our patients was known to have sarcoidosis. Hypercalcaemia due to sarcoidosis should be suspected in those who, after or during sun exposure, especially that of foreign sun holidays, develop symptoms such as nausea, vomiting, abdominal pain, constipation, polydipsia or polyuria. The more seriously ill patients in this group are at risk of being inappropriately diagnosed as suffering from sunstroke or heat exhaustion.

\section{References}

1. Taylor, R.L. \& Lynch, H.J. Seasonal influence of sunlight on the hypercalcaemia of sarcoidosis. Ann J Med 1963, 34: $221-227$.

2. Singer, F.R. \& Adams, J.S. Abnormal calcium homeostasis in sarcoidosis. N Engl J Med 1986, 315: 755-757.

3. Meyrier, A., Valeyre, D., Bouillon, R., Paillard, F., Battesti, J.P. \& Georges, R. Resorptive versus absorptive hypercalciuria in sarcoidosis: Correlations with 25 hydroxy vitamin $\mathrm{D}_{3}$ and 1,25 dihydroxy vitamin $D_{3}$ and parameters of disease activity. $Q J$ Med 1985, 54: 269-281.

4. Papapoulos, S.E., Clemens, T.L., Fraher, L.J., Lewin, I.G., Sandler, L.M. \& O'Riordan, J.L.H. 1,25 dihydroxycholecalciferol in the pathogenesis of the hypercalcaemia of sarcoidosis. Lancet 1979, i: 627-630.

5. Barbour, G.L., Coburn, J.W., Slatopolsky, E., Norman, A.W. \& Horst, R.L. Hypercalcaemia in an anephric patient with sarcoidosis: evidence for extra-renal generation of 1,25 dihydroxyvitamin D. $N$ Engl J Med 1981, 305: 440-443. 
6. Adams, J.S., Sharma, O.P., Gacad, M.A. \& Singer, F.R. Metabolism of 25-hydroxyvitamin $\mathrm{D}_{3}$ by cultured pulmonary alveolar macrophages in sarcoidosis. J Clin Invest 1983, 72: 1856-1860.

7. Mason, R.S., Frankel, T., Chan, Y.L., Lissner, D. \& Posen, S. Vitamin D conversion by sarcoid lymph node homogenate. Ann Intern Med 1984, 100: 59-61.
8. Sandler, L.M., Winearls, C.G., Fraher, L.J., Clemens, T.L., Smith, R. \& O'Riordan, J.L.H. Studies of the hypercalcaemia of sarcoidosis: effect of steroids and exogenous vitamin $D_{3}$ on the circulating concentration of 1,25 dihydroxyvitamin $D_{3} . Q J$ Med 1984, 53: 165- 180.

9. McCormick, P.A., Malone, D., Fitzgerald, M.X. \& Fitzgerald, O. Pancreatitis in sarcoidosis. Br Med J 1985, 290: 1472-1473. 